\title{
The effect of implementing self-management plan on self- concept of family caregivers of multiple sclerosis patients
}

\author{
Soheila Banitalebi $^{\circledR}$, Shahram Etemadifar ${ }^{(\mathbb{D}}$, Soleiman Kheiri ${ }^{(\mathbb{D}}$, Reza Masoudi $^{4^{*}}$ \\ ${ }^{1}$ MSc in Nursing, School of Nursing and Midwifery, Shahrekord University of Medical Sciences, Shahrekord, Iran. \\ ${ }^{2}$ Assistant Professor, Community-oriented Nursing Midwifery Research Center, Department of Adult and Geriatric Nursing, \\ School of Nursing and Midwifery, Shahrekord University of Medical Sciences, Shahrekord, Iran. \\ ${ }^{3}$ Professor of Biostatistics, Modeling in Health Research Center, Shahrekord University of Medical Sciences, Shahrekord, Iran. \\ ${ }^{4}$ Associate Professor, Community-oriented Nursing Midwifery Research Center, Department of Adult and Geriatric Nursing, \\ School of Nursing and Midwifery, Shahrekord University of Medical Sciences, Shahrekord, Iran.
}

*Corresponding Author: Reza Masoudi, Tel: +9838133335648, Fax: +98-3813346714, Email: Masoodi1383@yahoo.com

\begin{abstract}
Background and aims: Caring for patients with multiple sclerosis causes family caregivers many problems and challenges. Self-management interventions can facilitate the caring process and increase the quality of patient care. Therefore, the aim of this study was to investigate the effect of a self-management program on Self-concept of the family caregivers of multiple sclerosis patients.

Methods: This quasi-experimental study was conducted in 2018 at the MS Treatment Center of Shahrekord. The samples were selected through convenience sampling method. First, participants were assigned to two groups of men and women by stratified random sampling, and then men and women were assigned randomly to intervention $(n=35)$ and control $(n=35)$ groups. For the intervention group, the selfmanagement program was implemented twice a week in 8 sessions. Data collection was performed using the Coopersmith self-concept Inventory in two groups before, immediately after, and three months after the intervention. Data were analyzed by SPSS version 16.0. Results: The mean scores of self-concept in the intervention and control groups before the intervention were $72.6 \pm 9.1$ and $72 \pm 10.6$, respectively. There was no significant difference between the mean score of self-concept between the intervention and control groups before the intervention $(P>0.05)$. The mean scores of self-concept immediately after the intervention in the two groups were $86.4 \pm 9.2$ and $73 \pm 10.6$, and three months after the intervention, they were $103 \pm 7.4$ and $73.9 \pm 10.5$, respectively. A significant increase in the scores of self-concept in the intervention group $(P<0.001)$ was observed. Moreover, the independent $t$ test showed a significant difference in the two groups immediately after and three months after the intervention $(P<0.001)$.

Conclusion: Self-management program increased the self-concept of multiple sclerosis (MS) patients' caregivers. Therefore, selfmanagement can play a critical role in improving the quality of life of family caregivers and coping with the physical and psychological stress related to their caring role.

Keywords: Multiple sclerosis, Caregivers, Self-management Plan, Self-concept
\end{abstract}

Received: 21 September 2019, Accepted: 28 October 2019, ePublished: 29 April 2020

\section{Introduction}

Multiple sclerosis (MS) is one of the most common inflammatory diseases that affects the nervous system. It is one of the most common neurologic disorders in the world that affects many young people, and in many countries, it is the leading cause of non-traumatic neurological disability in the young. MS is a chronic inflammatory disease characterized by progressive demyelination of the central nervous system via the immune system $(1,2)$. With the onset of the disease, the family is greatly affected and 5 to 10 years after diagnosis, there is a significant and noteworthy difference in normal family functioning, so that the disease, both acute and chronic, has severe effects on the present and future life of the patient's family. The ways the family members adapt to this new course of life involves shock, denial, sadness, fear, anxiety, anger, guilt, and often hopelessness; these problems would inevitably lead to stressful situations for the family that suffer from numerous disorders (3). In recent therapies, political and economic changes have led to shifts of care towards caregivers and increased responsibility of family and friends $(4,5)$. In the United States, more than 44 million people provide unpaid care for their relatives and friends (6) Generally, the care is provided by a close family member, often the spouse or child. Approximately 30\% of people with MS who need support are assisted in various ways, and $80 \%$ of the care is provided by families (7).

Although the caring role of caregivers can increase their sense of kindness and love and provide them with benefits such as greater intimacy in family relationships, meaning in

(C) 2020 The Author(s); Published by Shahrekord University of Medical Sciences. This is an open-access article distributed under the terms of the Creative Commons Attribution License (http://creativecommons.org/licenses/by/4.0), which permits unrestricted use, distribution, and reproduction in any medium, provided the original work is properly cited. 
life, respect for themselves and others, and self-satisfaction, studies show that caring responsibility puts a great amount of pressure on caregivers' physical and mental health $(3,8)$. The day-to-day support that family members provide for their spouse, parents, and partner who is suffering from the disease has significant physical, psychological, and economic costs and consequences such as inability to solve problems, economic stresses, changes in the roles of the family, threats, changes in life expectancy and feelings of loneliness which include fear of being abandoned. The emergence of a chronic illness in the family is like the birth of a new baby with special needs that will compete with those of the other children for family resources $(9,10)$. Because most of the activities of the family caregiver take place at home, these caregivers are underestimated and sometimes neglected. Due to the frustrating nature of the disease and psychological, social and physiological needs of MS patients, caregivers endure high levels of ambiguity and face many challenges (7). One of the very important components in the process of caring for patients with chronic diseases such as MS is paying attention to the concept of a caregiver's self-concept in patient care. Selfconcept is the degree of approval and value that one feels about one's self or judgment about one's self-worth (11). Self-concept is defined as the values an individual places on his or her own characteristics, abilities, and actions, and it is one of the factors that has fueled the emergence of ideas about patient caregivers (12). In recent years, self-concept has been a major driver of happiness and enjoyment in different cultures for all kinds of social problems (13). Due to the debilitating nature of MS, the disease affects not only the physical and social aspects of patients and their caregivers' lives but also their psychological, cognitive, and affective aspects, including mental health, and self-concept. Low self-concept has negative effects on interpersonal relationships, emotions, and performance and also reduces one's ability to perform family and social roles $(14,15)$. Results of studies indicate that anxiety and self-concept of caregivers of patients with MS is not at a very good level, and therefore, any frustration and depression at the point of confrontation with one's self-concept and disgust can affect these vulnerable populations. In addition, by improving self-concept, the mental health and quality of life of patients and their caregivers are promoted. Patients with high self-concept are able to cope with illness, have resilience, and fulfill their responsibilities. They are less influenced by negative beliefs because they believe they can influence their present and future conditions (12). Given the fact that illnesses caused by cognitive and psychological changes have a huge negative impact on the self-concept of patients and their caregivers, conducting studies that can plan programs for possible improvement of self-concept based on the actual conditions and needs of individuals is one of the health priorities of today's society (16). On the other hand, it should always be kept in mind that in the face of chronic illnesses, health care providers need to have higher adaptability when faced with issues and problems. Therefore, it is essential to enhance caregivers' ability to work with patients as a permanent patient.

One of the issues that is always considered by health care professionals for optimal management of health issues is the attention to self-management programs. Self-management is an issue that plays an important role in empowering individuals to manage their behavior and performance in social contexts (17). Management is a dynamic, interactive, day-to-day process in which people work to manage chronic illness; self-management refers to one's ability to manage family, community and health care issues, symptom management, treatment, lifestyle changes, and psychological, social, cultural, and spiritual consequences of health conditions (18). In fact, self-management is a dynamic process in which people regularly manage chronic illness and require the ability to monitor disease and develop and use cognitive, behavioral, and emotional strategies to maintain a satisfactory quality of life. Self-management is, therefore, distinct from selfcare and broadly promotes healthy lifestyle behaviors in individuals to achieve optimal growth and development of preventive strategies to promote or maintain health (19). In this regard, Peñarrieta et al stated that family-centered selfmanagement is of great value and importance because selfmanagement in people with chronic illnesses is still poor, especially with regard to the knowledge about the disease. Therefore, the management of signs and symptoms needs to be further explored through qualitative and quantitative approaches to enhance family-centered self-management skills by discovering other educational strategies (17). Selfmanagement processes in living with chronic illness were first identified by Strauss and Corbin. They identified three self-management tasks that included managing disease problems (such as taking medication and attending medical centers), behavioral management (such as lifestyle adaptation or roles of life), and emotional management (such as the processing of feelings from chronic illness). Moreover, several self-management skills such as problemsolving, decision making, resource utilization, and collaboration with healthcare providers were suggested for the improvement of self-efficacy (19). In a study by Heidari et al, the effect of self-management program on self-efficacy of patients with chronic obstructive pulmonary disease was investigated based on the $5 \mathrm{~A}$ 's model (ask, advise, assess, assist, and arrange). Considering the effectiveness of self-management programs, to promote patients' self-efficacy, they recommended the use of these interventions in other chronic diseases in future studies (20). Moreover, Brunner recommended that caregivers should develop life management skills to help themselves and other family members (those with chronic illness) to use and receive training and support programs, learn the adaptation responses, and use different economic, cultural, 
and personality resources (21).

Considering the results of studies on self-management, a general self-management program in chronic diseases can be considered in several dimensions (Table 1) $(18,19,22)$.

Given the multiple impacts of MS on patients, families, and society, which overshadow the self-concept of family caregivers, it is essential that the health services provided for patients and families are effective and based on their problems and challenges, the researcher sought to find an effective way to determine the impact of self-management on the self-concept of family caregivers of MS patients.

\section{Materials and Methods}

This quasi-experimental study investigated the effect of a self-management program on the self-concept of family caregivers of MS patients. The current study was conducted on family caregivers of MS patients in the MS Treatment Center of Shahrekord via community advertising in 2018. To qualify for inclusion in the study, family caregivers of patients with MS had to satisfy the following criteria: giving informed consent to participate in the study, being eligible for patient care, living with the patient, being over 18 years of age (23), being literate, spending 3-8 hours of care per day (23), caring for patients with the type of relapsing-remitting MS, several months of experience of caring for a family member, caring for a patient who has only MS, caring for only one patient, not attending family training sessions (any other research projects), no history of severe physical illnesses and known mental disorders (based on medical records). The exclusion criteria included: not having willingness to continue participation in the study, contact between the participants of the intervention and control group, death of the patient, assigning responsibility for the care of a person with MS by another person or care
Table 1. Dimensions of self-management

\begin{tabular}{ll}
\hline Dimensions of self-management & Self-management techniques and strategies \\
\hline $\begin{array}{l}\text { 1. Care knowledge management } \\
\text { 2. Managing of the care plan }\end{array}$ & Problem-solving, educational participation \\
$\begin{array}{l}\text { 3. Self-care management } \\
\text { 4. Manage adaptation skills }\end{array}$ & Problem-solving, educational participation \\
$\begin{array}{l}\text { 5. Spiritual management } \\
\text { 6. Managing emotions }\end{array}$ & Rain of thoughts, group discussion \\
$\begin{array}{l}\text { 7. Managing social challenges } \\
\text { and providing resources }\end{array}$ & Peer groups, rain of thoughts \\
\hline
\end{tabular}

centers, and failure to participate in more than one session of the training class. In this study, the sample size was determined to be 70 subjects (35 in each group) according to statistical formulas used in similar studies (13) with a confidence interval of $95 \%$ and power of $90 \%$. Finally, the sample size was estimated to be 35 in each group, taking dropouts into account. The samples were selected using the convenience sampling method; the sampling continued until the samples were completed. First, participants were assigned to two groups of men and women by Stratified random sampling, and then men and women were assigned randomly to intervention $(\mathrm{n}=35)$ and control $(\mathrm{n}=35)$ groups (Figure 1).

$$
n=\frac{2\left(Z_{1-\frac{\alpha}{2}}+Z_{1-\beta}\right)^{2} \sigma^{2}}{d^{2}}
$$

Z1 $-\alpha / 2=1.96 \alpha=0.05 \beta=0.1 \quad \sigma=6$

Data were collected using a demographic questionnaire and Coopersmith self-concept questionnaire. Demographic Information of the participants included age of caregiver, age of the patient, gender of caregiver, education level of

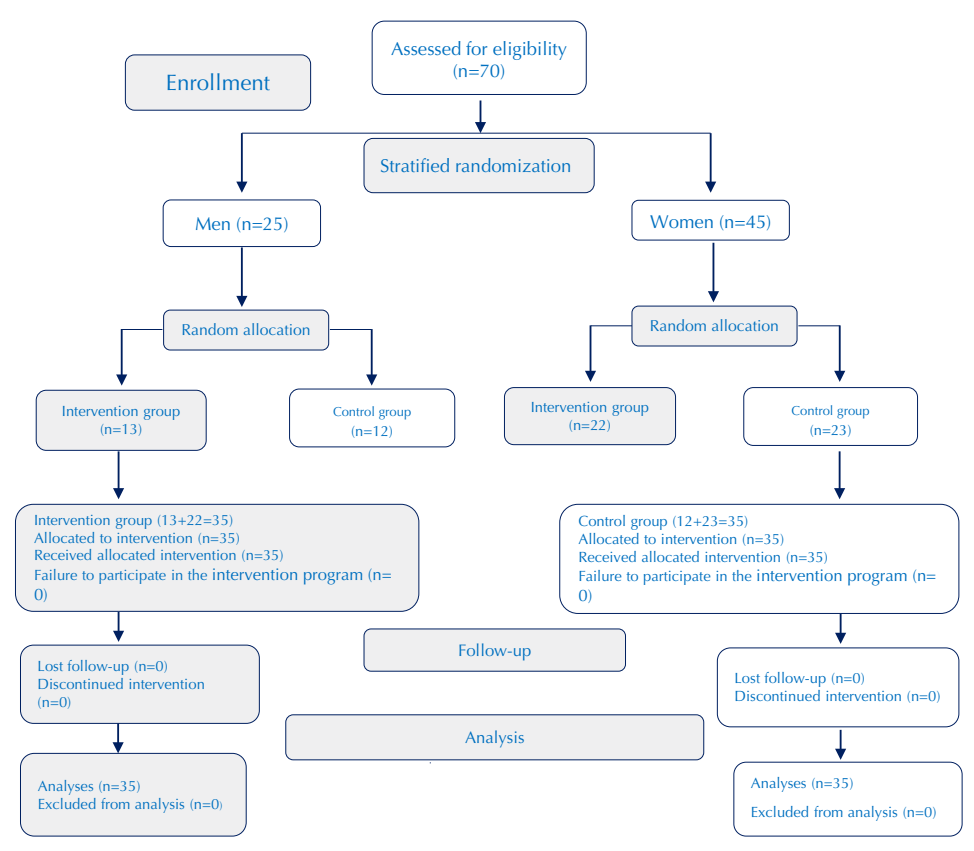

Figure 1. The flowchart of the study procedure. 
caregiver, education level of patient, duration of patient's illness, occupation of caregiver, and marital status of caregiver. The Coopersmith Self-concept inventory contains 35 statements about which the subjects should express their true feeling based on four choices ranging from strongly agree, agree, disagree, and strongly disagree. The overall self-concept score ranged from 35 to 140; all sentences in this questionnaire are formulated to be applicable to children of 10 years of age. In a study by Masoodi et al, the validity and reliability of the questionnaire were investigated and Cronbach's alpha was determined to be 0.87 (16) and in another study by Daraei, Cronbach's alpha was determined to be 0.82 (24). In this study, the reliability of this questionnaire was measured by Guttman split-half coefficient and Cronbach's alpha was calculated to be 0.83 .

The purpose of the self-management program in this study was to develop a program based on the framework identified by Strauss and Corbin including selfmanagement processes and the educational and skill needs of family caregivers of patients with MS (Table 2). The program was designed based on the supportive nursing system and the educational partnership, which included a training package and a set of self-management programs implemented in 8 sessions of 90 minutes (25) twice a week by the researcher. The intervention was performed at the MS Treatment Center of Shahrekord via community advertising. Before the intervention, the Coopersmith self-concept questionnaire was completed by the control group and the intervention group after obtaining written informed consent. Immediately after completing the selfmanagement program, the questionnaire was completed again by the two groups and the intervention group followed the three-month follow-up program.

Follow-up was completed using the self-report checklist and phone calls. After three months of follow up, the questionnaire was completed by both groups again. For the control group, during the intervention, routine communitybased general education about MS was continued, and the study variables in this group were examined concurrently with the intervention group.

In order to observe the ethical considerations of the research, after completing the intervention, the researcher invited the control group caregivers by a phone call to participate in the training sessions and the self-management

Table 2. Content of self-management program for caregivers of patients with multiple sclerosis

\begin{tabular}{|c|c|c|c|c|c|}
\hline Time & Charge & Procedure & Objectives & Session Content & Sessions \\
\hline $\begin{array}{l}\text { An hour } \\
\text { and a half }\end{array}$ & $\begin{array}{l}\text {-Researcher } \\
\text { - Nursing PhD }\end{array}$ & $\begin{array}{l}\text { Lecture, questions } \\
\text { and answers, } \\
\text { group discussion }\end{array}$ & $\begin{array}{l}\text { 1. Knowledge about the disease } \\
\text { 2. Monitor and manage symptoms } \\
\text { 3. Manage symptoms and side effects of } \\
\text { the drugs. }\end{array}$ & $\begin{array}{l}\text { - Getting acquainted with MS } \\
\text { - Symptoms of the disease } \\
\text { - Drug treatment }\end{array}$ & $\begin{array}{l}\text { First session } \\
\text { Knowledge of care }\end{array}$ \\
\hline $\begin{array}{l}\text { An hour } \\
\text { and a half }\end{array}$ & Researcher & $\begin{array}{l}\text { Problem-solving, } \\
\text { educational } \\
\text { participation, } \\
\text { lecture }\end{array}$ & $\begin{array}{l}\text { 1. Increased readiness for patient care } \\
\text { 2. Become a professional } \\
\text { 3- Improving caregiver confidence }\end{array}$ & $\begin{array}{l}\text { - Explain the role of caregiver } \\
\text { - Family challenges and problems } \\
\text { - Powerful and clever design } \\
\text { - Importance of diet }\end{array}$ & $\begin{array}{l}\text { Second session } \\
\text { Planning for care }\end{array}$ \\
\hline $\begin{array}{l}\text { An hour } \\
\text { and a half }\end{array}$ & $\begin{array}{l}\text {-Researcher } \\
\text {-Nursing PhD }\end{array}$ & $\begin{array}{l}\text { Lecture, questions } \\
\text { and answers, } \\
\text { group discussion, } \\
\text { peer group }\end{array}$ & $\begin{array}{l}\text { 1. Finding fun new activities } \\
\text { 2. Learn personal strengths and limitations } \\
\text { 4. Positive Thinking } \\
\text { 5. Identify the symptoms of stress, insomnia, } \\
\text { acupuncture }\end{array}$ & $\begin{array}{l}\text { - Taking care of yourself } \\
\text { - Exercise and activity } \\
\text { - A proper diet } \\
\text { - Mental support } \\
\text { - Balance between work and life }\end{array}$ & $\begin{array}{l}\text { Third session } \\
\text { Caregiver' self-care }\end{array}$ \\
\hline $\begin{array}{l}\text { An hour } \\
\text { and a half }\end{array}$ & Researcher & $\begin{array}{l}\text { Problem-solving, } \\
\text { educational } \\
\text { participation, } \\
\text { lecture }\end{array}$ & $\begin{array}{l}\text { 1.Improve patient communication skills and } \\
\text { adaptability in caring of patient } \\
\text { 2. Reduce stress and distress } \\
\text { 3. Flexibility } \\
\text { 4. Balance between needs and desires, } \\
\text { professional discipline }\end{array}$ & $\begin{array}{l}\text { - Developing coping skills } \\
\text { - Problem-solving methods } \\
\text { - Time management } \\
\text { - Lifestyle modifications } \\
\text { - Coping skills training } \\
\text { - Creativity }\end{array}$ & $\begin{array}{l}\text { Fourth session } \\
\text { Adaptation skills } \\
\text { management }\end{array}$ \\
\hline $\begin{array}{l}\text { An hour } \\
\text { and a half }\end{array}$ & Researcher & $\begin{array}{l}\text { Lecture, thought- } \\
\text { provoking } \\
\text { questions and } \\
\text { answers }\end{array}$ & $\begin{array}{l}\text { 1. The adaptive application of spiritual } \\
\text { information in problem solving } \\
\text { 2.Creating a sense of purpose } \\
\text { 3. To appreciate life. }\end{array}$ & $\begin{array}{l}\text {-Maintaining self-spirituality } \\
\text { - High power verification } \\
\text { - Nurturing spirituality } \\
\text { - Praying } \\
\text { - Being a part of the spiritual world. }\end{array}$ & $\begin{array}{l}\text { Fifth session } \\
\text { Spiritual management } \\
\text { of caregivers }\end{array}$ \\
\hline $\begin{array}{l}\text { An hour } \\
\text { and a half }\end{array}$ & Researcher & $\begin{array}{l}\text { Problem-solving, } \\
\text { questions and } \\
\text { answers }\end{array}$ & $\begin{array}{l}\text { 1. Prevention of isolation } \\
\text { 2. Increase confidence } \\
\text { 3. Emotional control } \\
\text { 4. New and positive outlook for life } \\
\text { 5. Being grateful for emotions }\end{array}$ & $\begin{array}{l}\text {-Methods of controlling unwanted } \\
\text { emotions } \\
\text { - Maintaining self-worth } \\
\text { - Emotion processing and sharing }\end{array}$ & $\begin{array}{l}\text { Sixth session } \\
\text { Management } \\
\text { of Emotions }\end{array}$ \\
\hline $\begin{array}{l}\text { An hour } \\
\text { and a half }\end{array}$ & Researcher & $\begin{array}{l}\text { Lecture, questions } \\
\text { and answers, } \\
\text { group discussion }\end{array}$ & $\begin{array}{l}\text { 1. Increase information about the support } \\
\text { from available resources } \\
\text { 2. Use of public services } \\
\text { 3. Seeking support from family }\end{array}$ & $\begin{array}{l}\text { - Introduction resources } \\
\text { - Support and training services } \\
\text { - Create a group of peers with } \\
\text { similar experiences }\end{array}$ & $\begin{array}{l}\text { Seventh session } \\
\text { Social support } \\
\text { and use of support } \\
\text { resources }\end{array}$ \\
\hline $\begin{array}{l}\text { An hour } \\
\text { and a half }\end{array}$ & Researcher & $\begin{array}{l}\text { discussion, } \\
\text { questions and } \\
\text { answers }\end{array}$ & & $\begin{array}{l}\text { Summary of content listed in } \\
\text { previous sessions }\end{array}$ & Eighth session \\
\hline
\end{tabular}


program was provided for the control group in the form of a booklet.

Collected data were entered into SPSS version 16.0, and then they were described by descriptive statistics, including mean and standard deviation for quantitative variables as well as frequency and percentage for qualitative variables. Independent $t$ test was used to analyze and compare the mean score of self-concept before, immediately, and three months after the intervention between the two groups. Moreover, repeated measures ANOVA was used to determine the trend of changes within each group. Additionally, $P$ values less than 0.05 were considered statistically significant.

\section{Results}

A total of 70 caregivers of MS patients, 35 in the intervention group and 35 in the control group, participated in this study. Based on the results, $64.3 \%$ of the caregivers were female and $35.7 \%$ were male. The age of the caregivers ranged from 19 to 67 years with a mean age of $41.8 \pm 11.8$ years and the age of patients ranged from 21 to 60 years with a mean age of $36.3 \pm 9.2$. In terms of the education of caregivers, $54.3 \%$ of the intervention group and $57.5 \%$ of the control group had a high school diploma and in terms of patient's education level, $48.6 \%$ of the intervention group and $60 \%$ of the control group had a high school diploma. In terms of homogeneity, $37.1 \%$ of the intervention group were female patients with a male caregiver and 57.1\% of the control groups were male patients with a female caregiver. Duration of disease by year in the intervention group was in the range of 1 to 20 years with a median of $6(2-10)$ and in the control group in the range of 3 to 18 years with a median of $7(5-10)(P=0.12)$. In terms of the occupation, $48.6 \%$ of the intervention group and $51.4 \%$ of the control group were unemployed and in terms of marital status, $88.6 \%$ of the intervention group and $77.1 \%$ of the control group were married (Tables 3 and 4).

The means and standard deviations of self-concept score at 3 intervals (before, immediately after, and three months after intervention) in the intervention group were 72.6 59.1 , $86.4 \pm 9.2$, and $103 \pm 7.4$, respectively, and in the control group, they were $72 \pm 10.6,73 \pm 10.6$, and $73.9 \pm 10.5$, and the mean change (and standard deviation) was $30.48 \pm 7.32$ in the intervention group and it was $1.88 \pm 0.96$ in the control group. There was no significant difference in the self-concept score before interventional program between the intervention and control groups $(P=0.819)$; however, there was a significant difference in the mean self-concept score immediately and three months after the intervention between the intervention and control groups $(P=0.001)$. The intervention group had a higher self-concept score than the control group. Self-concept score significantly increased in both groups during the study. Moreover, there was a significant difference in self-concept score between the two groups, with a mean increase of 30 points in the intervention group and 2 points in the control group (Table 5).

Considering the significant values (Tables 3 and 4 ) of the intervention and control groups in terms of quantitative

Table 4. Mean Age of Caregivers and Patients with MS in the Intervention and Control Groups

\begin{tabular}{lccc}
\hline \multirow{2}{*}{ Variable } & \multicolumn{2}{c}{ Group } & \\
\cline { 2 - 3 } & $\begin{array}{c}\text { Intervention Group } \\
\text { Mean } \pm \text { SD }\end{array}$ & $\begin{array}{c}\text { Control Group } \\
\text { Mean } \pm \text { SD }\end{array}$ & \\
\hline Age of caregiver (year) & $41 \pm 11.9$ & $42.7 \pm 11.7$ & 0.539 \\
Age of patient (year) & $35.2 \pm 8.4$ & $37.4 \pm 10$ & 0.323 \\
\hline
\end{tabular}

Table 3. Demographic characteristics of the caregivers of patients with multiple sclerosis in intervention and control groups

\begin{tabular}{|c|c|c|c|c|c|c|}
\hline \multirow{2}{*}{ Variable } & \multirow{2}{*}{ Levels } & \multicolumn{2}{|c|}{ Intervention Group } & \multicolumn{2}{|c|}{ Control Group } & \multirow{2}{*}{$P$ Value } \\
\hline & & No. & $\%$ & No. & $\%$ & \\
\hline \multirow{2}{*}{ Gender of caregiver } & Male & 15 & 42.9 & 10 & 28.6 & \multirow{2}{*}{0.212} \\
\hline & Female & 20 & 57.1 & 25 & 71.4 & \\
\hline \multirow{3}{*}{ Education level of caregiver } & Under high school diploma & 10 & 28.6 & 7 & 20 & \multirow{3}{*}{0.657} \\
\hline & High school diploma & 19 & 54.3 & 20 & 57.1 & \\
\hline & Academic & 6 & 17.1 & 8 & 22.9 & \\
\hline \multirow{3}{*}{ Education level of patient } & Under high school diploma & 9 & 25.7 & 4 & 11.4 & \multirow{3}{*}{0.302} \\
\hline & High school diploma & 17 & 48.6 & 21 & 60 & \\
\hline & Academic & 9 & 25.7 & 10 & 28.6 & \\
\hline \multirow{4}{*}{ Homogeneity } & Both of them female & 9 & 25.7 & 5 & 14.3 & \multirow{4}{*}{0.188} \\
\hline & Both of them male & 1 & 2.9 & 0 & 0 & \\
\hline & Female (patient) and male (caregiver) & 13 & 37.1 & 10 & 28.6 & \\
\hline & Male (patient) and female (caregiver) & 12 & 34.3 & 20 & 57.1 & \\
\hline \multirow{5}{*}{ Occupation } & Student & 1 & 2.9 & 1 & 2.9 & \multirow{5}{*}{0.849} \\
\hline & Unemployed & 17 & 48.6 & 18 & 51.4 & \\
\hline & Employed & 2 & 5.7 & 4 & 11.4 & \\
\hline & Free & 8 & 22.9 & 8 & 22.9 & \\
\hline & Retired & 7 & 20 & 4 & 11.4 & \\
\hline \multirow{4}{*}{ Marital status } & Single & 4 & 11.4 & 4 & 11.4 & \multirow{4}{*}{0.244} \\
\hline & Married & 31 & 88.6 & 27 & 77.1 & \\
\hline & Divorced & 0 & 0 & 1 & 2.9 & \\
\hline & Widow & 0 & 0 & 3 & 8.6 & \\
\hline
\end{tabular}


Table 5. Mean scores of self-concept in family caregivers of patients with MS in intervention and control groups

\begin{tabular}{|c|c|c|c|c|}
\hline \multirow{2}{*}{ Variable } & \multirow{2}{*}{ Time } & Intervention group & Control group & \multirow{2}{*}{$P$ Value $^{\mathrm{a}}$} \\
\hline & & Mean \pm SD & Mean \pm SD & \\
\hline \multirow{5}{*}{ Self-concept } & Before intervention & $72.6 \pm 9.1$ & $72 \pm 10.6$ & 0.819 \\
\hline & Immediately after intervention & $86.4 \pm 9.2$ & $73 \pm 10.6$ & 0.001 \\
\hline & Three months after intervention & $103 \pm 7.4$ & $73.9 \pm 10.5$ & 0.001 \\
\hline & Repeated measures ANOVA & $P=0.001$ & $P=0.001$ & \\
\hline & Changes during study & $30.48 \pm 7.32$ & $1.88 \pm 0.96$ & \\
\hline
\end{tabular}

Independent $t$ test.

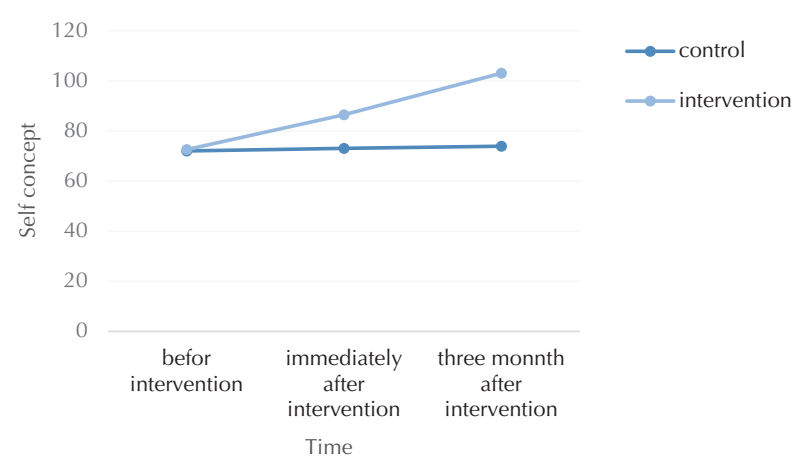

Figure 2. Mean scores of self-concept in family caregivers of patients with MS in intervention and control groups.

demographic characteristics (age of caregivers, age of patients, and duration of illness) and qualitative variables (gender, occupation, education level, and marital status), there was no significant difference between intervention and control groups.

Based on the results of an independent $t$ test, there was no significant difference in the mean self-concept score before the interventional program between the intervention and control groups $(P=0.819)$. There was a significant difference in the mean self-concept score immediately after the interventional program and 3 months after the interventional program between the two groups $(P=0.001)$. According to the results of repeated measures ANOVA, the mean self-concept scores at 3 intervals (before, immediately after, and three months after the interventional program) were significantly different between the intervention and control groups $(P=0.001)$. There was a statistically significant difference between the intervention and control groups $(P=0.001)$. It can be concluded that the trend of increase in self-concept scores was different in two groups, indicating a significant increase in the intervention group $(P=0.001)$.

\section{Discussion}

The implementation of the self-management program made significant changes in the self-concept of caregivers of MS patients. The results of this study showed that the majority of family caregivers of patients with MS were female, unemployed, and married. Most of them had a high school diploma with a mean age of $41.8 \pm 11.8$ years and a history of illness of over 6 years. In Iranian society and culture, the care of patients, especially the disabled ones, is often handled by women, who are often unemployed and is considered a part of the household and home affairs. In this regard, Díaz et al state in their study that there is a significant relationship between higher perceived burden and poorer general health in women, especially when less social support is available (26). Studies in Iran and other countries also show that women are mostly the main caregivers of their patients at home, and on average, these caregivers are middle-aged, married, and housewives (13, 27,28). The findings of this study are in line with a study conducted by Masoodi et al on the effects of a familycentered empowerment model on perceived satisfaction and self-concept of caregivers of MS patients. The results of this study showed that $61.76 \%$ of caregivers were female, $52 \%$ were between 30 and 60 years, $85.29 \%$ were married and $64.7 \%$ had high school diploma or higher education in the control group. Additionally, $55.88 \%$ of caregivers were female, $40 \%$ were between 30 and 60 years old, $71.42 \%$ were married and $82.58 \%$ had high school diploma and higher education in the intervention group. Moreover, the results of independent samples $t$ test showed a significant difference in the two groups after the intervention $(P=0.001)$. In the intervention group, a significant increase was observed in perceived satisfaction and self-concept of family caregivers $(P=0.001)$, while in the control group, there was no significant difference in the perceived satisfaction and self-concept of the family caregivers of patients after three months (13). In addition, Rahimi conducted a study to evaluate the effects of applying a continuous care model on self-esteem in hemodialysis patients (29), the results of which showed that the implementation of the follow-up care model caused a significant difference between the mean scores of self-concept before and after the intervention $(P=0.0001)$. The mean increased from 63.6 (before intervention) to 79.6 (after intervention), the results of this study are consistent with the present study. Furthermore, the results obtained by Ebrahimi et al (12) and Sharifi Neyestanak et al (30) are in agreement with the results of the present study. Ebrahimi et al stated in his study that self-concept is a multifaceted concept with different dimensions that interact with each other. One of the most important dimensions is empowerment which includes the subcategories of resilience, supportive family, 
and supportive community. It results from accepting illness, taking responsibility, living with hope, having a supportive family, enhancing self-esteem, improving status in the family, gaining social support, having a stress-free job, improving family relationships, and communicating with peers with similar experiences. Therefore, by enhancing selfconcept and the sense of value, patients and their caregivers can be helped at individual, family, and social levels to achieve the empowerment targeted by health systems (12). Sharifi Neyestanak et al stated in his study that people with limited ability to adapt to different situations are more likely to have problems than healthy individuals, and one of the effective ways to achieve better adaptation is to help individuals achieve high self-concept. The results showed that only $16.2 \%$ of participants had high self-concept, while the majority (71.6\%) had moderate self-concept. There is also a significant relationship between self-concept and marital status, occupational status, and duration of illness (30). In addition, the results of studies conducted by Zendehtalab and Norouzi (14), Robati and Shareh (31), and Jones et al (32) are consistent with the present study. The results obtained by Robati and Shareh showed that cognitive-behavioral interventions significantly reduced anxiety $(P<0.001)$ and increased general self-concept $(P=0.001)$, general self-concept $(P=0.002)$, family-related self-concept $(P=0.005)$, and professional self-concept $(P=0.003)$ compared to the control group; however, no significant difference was found in social self-concept scores $(P=0.388)$.

In a study by Kelly et al (33), the effect of familybased interventions on self-concept after brain injury was investigated. They concluded that using a family-based intervention did not result in self-concept improvement, either globally or across self-concept domains. In another study, Kidd et al pointed out that self-management interventions had a significant effect on the improvement of quality of life as well as the symptoms of depression and anxiety. The small number of self-management interventions available to include in this study indicates a significant gap in the literature. Further studies with larger sample size are needed to analyze subgroups, determine which SMI components are best for different types of MS, and examine the optimal way of presenting it.; In addition, the advances in the field of SMI would be to develop agreed guidelines for researchers and physicians on best practices in designing and reporting studies in this area and to consider the important role of patient caregivers (34).

In the present study, the effect of self-management program on the improvement of the mean score of selfconcept in the intervention group was more pronounced, this indicates the appropriateness of the program and the use of hybrid and multidimensional self-management interventions. The intervention used in this study increased self-concept and improved caregivers' ability to perform daily activities by implementing a more comprehensive educational-supportive program (care knowledge, selfcare, care planning, emotion management, adaptation skills, spiritual management, and social management). It also enhanced independence, caregiver's awareness, stress control, adaptation, and disease management. These statements show that the greater the effort to educate the self-management program in the community of patient' caregivers, the stronger the spirit of adaptation and selfconcept, thereby enhancing caregivers' quality of life and health status.

\section{Conclusion}

Family caregivers of patients with chronic diseases, as helpers of patients, are subject to great stress. In fact, self-management is an important factor in improving the health status of caregivers, and using interventions such as self-management program with regard to their educational and therapeutic needs can improve the self-concept of caregivers and help them to change their attitude toward symptoms, change behaviors, and relieve stress. It also helps caregivers in caring and enhancing their motivation to change their behavior, increase their quality of life and promote health, which is the goal of all communities, families, and individuals. Considering the low cost, safety and effectiveness of these interventions, they can help to improve the quality of life of family caregivers of patients with chronic diseases such as MS.

\section{Application of Research Findings in Clinical Trial}

The self-management support program can improve caregivers' self-concept, reduce negative caring outcomes, increase caregivers' knowledge of caring in MS, and improve the quality of life in caregivers of these patients. It is recommended that family caregiver education be included in routine treatment plans for these patients. It is also suggested that family caregiver training and support units be established at health centers alongside the patient education unit so that caregivers can receive the necessary advice.

Conflict of Interests

The authors declare that there is no conflict of interests.

Ethical Approval

Ethical considerations in this study included obtaining permission from the Ethics Committee of Shahrekord University of Medical Sciences (IR.SKUMS.REC.280) and obtaining written consent from the participants to participate in the study.

\section{Acknowledgments}

The data presented in this manuscript were obtained from research project (grant number: 3948) conducted in Shahrekord University of Medical Sciences. We would like to thank all of the MS patients and the dedicated and hardworking personnel of the Multiple Sclerosis Society of Iran who patiently assisted the researcher in conducting this study. 


\section{References}

1. Minagar A. Preface. In: Minagar A, ed. Multiple Sclerosis. San Diego: Academic Press; 2016. p. xv-xvi.

2. Browne P, Chandraratna D, Angood C, Tremlett H, Baker C, Taylor BV, et al. Atlas of multiple sclerosis 2013: a growing global problem with widespread inequity. Neurology. 2014;83(11):1022-4. doi: 10.1212/wnl.0000000000000768.

3. Uccelli MM. The impact of multiple sclerosis on family members: a review of the literature. Neurodegener Dis Manag. 2014;4(2):177-85. doi: 10.2217/nmt.14.6.

4. Katsavos S, Artemiadis AK, Zacharis M, Argyrou P, Theotoka I, Chrysovitsanou C, et al. Predicting caregiving status and caregivers' burden in multiple sclerosis. A short report. Neurol Res. 2017;39(1):13-5. doi: 10.1080/01616412.2016.1254942.

5. Fleisher J, Bondi S, Singleton-Garvin J, Lanoff M, Di Rocco A, Xie $S$, et al. Health literacy in Parkinson's disease caregivers. Neurology. 2016;86(16 Suppl):1-21.

6. Hillman L. Caregiving in multiple sclerosis. Phys Med Rehabil Clin N Am. 2013;24(4):619-27. doi: 10.1016/j. pmr.2013.06.007.

7. Dayapoğlu N, Tan M. The care burden and social support levels of caregivers of patients with multiple sclerosis. Kontakt. 2017;19(1):e17-e23. doi: 10.1016/j.kontakt.2016.12.001.

8. Ghane G, Ashghali Farahani M, Seyedfatemi N, Haghani H. Effectiveness of supportive educative program on the burden in family caregivers of hemodialysis patients. Journal of Urmia Nursing and Midwifery Faculty. 2017;14(10):885-95. [Persian].

9. Opara J, Brola W. Quality of life and burden in caregivers of multiple sclerosis patients. Physiother Health Act. 2018;25(1):916. doi: 10.1515/pha-2017-0002.

10. Nwoke MB, Onuigbo EN, Odo VO. Social support, self-efficacy and gender as predictors of reported stress among inpatient caregivers. Soc Sci J. 2017;54(2):115-9. doi: 10.1016/j. soscij.2016.08.001.

11. Hattie J. Self-Concept. Psychology Press; 2014. p. 304.

12. Ebrahimi Belil F, Alhani F, Ebadi A, Kazemnejad A. Explaining the concept of self-esteem in patients with chronic conditions based on the family-centered empowerment model: a directed content analysis. Iranian Journal of Psychiatric Nursing. 2017;5(2):23-39. doi: 10.21859/ijpn-05024. [Persian].

13. Masoodi R, Soleimani MA, Alhani F, Rabiei L, Bahrami N, Esmaeili SA. Effects of family-centered empowerment model on perceived satisfaction and self concept of multiple sclerosis patients care givers. Koomesh. 2013;14(2):240-8. [Persian].

14. Zendehtalab $\mathrm{H}$, Norouzi $\mathrm{H}$. Effects of educational interventions on self-esteem of multiple sclerosis patients. Ofogh-E-Danesh. 2014;20(2):121-6. [Persian].

15. Silvestri PR, BaglioniV, Cardona F, Cavanna AE. Self-concept and self-esteem in patients with chronic tic disorders: a systematic literature review. Eur J Paediatr Neurol. 2018;22(5):749-56. doi: 10.1016/j.ejpn.2018.05.008.

16. Masoodi R, Khayeri F, Safdari A. Effect of self- care program based on the Orem frame work on self concept in multiple sclerosis patients. Journal of Gorgan University of Medical Sciences. 2010;12(3):37-44. [Persian].

17. Peñarrieta Ml, Flores-Barrios $F$, Gutiérrez-Gómez $T$, PiñonesMartínez S, Resendiz-Gonzalez E, Quintero-Valle LM. Selfmanagement and family support in chronic diseases. J Nurs Educ Pract. 2015;5(11):73-80. doi: 10.5430/jnep.v5n11p73.

18. Fraser R, Ehde D, Amtmann D, Verrall A, Johnson KL, Johnson E, et al. Self-management for people with multiple sclerosis: report from the first international consensus conference, november 15, 2010. Int J MS Care. 2013;15(2):99-106. doi: 10.7224/1537-2073.2012-044.

19. Schulman-Green D, Jaser S, Martin F, Alonzo A, Grey $M$, McCorkle $R$, et al. Processes of self-management in chronic illness. J Nurs Scholarsh. 2012;44(2):136-44. doi: 10.1111/j.1547-5069.2012.01444.x.

20. Heidari M, Fayazi S, Borsi S, Vafaizadeh M. Effect of selfmanagement program on self-efficacy in patients with chronic obstructive pulmonary disease. Iran Journal of Nursing. 2016;29(99):45-55. doi: 10.29252/ijn.29.99.100.45. [Persian].

21. Brunner LS. Brunner \& Suddarth's Textbook of Medical-Surgical Nursing. Lippincott Williams \& Wilkins; 2014.

22. Eslami AA, Rabiei L, Abedi HA, Shirani M, Masoudi R. Coping skills of Iranian family caregivers' in caretaking of patients undergoing haemodialysis: a qualitative study. J Ren Care. 2016;42(3):162-71. doi: 10.1111/jorc.12166.

23. Etemadifar S, Bahrami M, Shahriari M, Farsani AK. The effectiveness of a supportive educative group intervention on family caregiver burden of patients with heart failure. Iran J Nurs Midwifery Res. 2014;19(3):217-23.

24. Daraei M. An investigation of the relationship between depression and self-esteem with academic performance. Yafteh. 2018;19(5):117-26. [Persian].

25. Pahlavanzadeh S, Dalvi-Isfahani F, Alimohammadi N, Chitsaz A. The effect of group psycho-education program on the burden of family caregivers with multiple sclerosis patients in Isfahan in 2013-2014. Iran J Nurs Midwifery Res. 2015;20(4):420-5. doi: 10.4103/1735-9066.161000.

26. Díaz M, Estévez A, Momeñe J, Ozerinjauregi N. Social support in the relationship between perceived informal caregiver burden and general health of female caregivers. Ansiedad y Estrés. 2019;25(1):20-7. doi: 10.1016/j.anyes.2019.04.001.

27. Rahnema S, Baghersad Z, Shirazi M, Chitsaz A, Etemedifar $M$. Association between family caregivers' quality of life and psychological capital of the patients with multiple sclerosis. Journal of Isfahan Medical School. 2016;34(377):335-40. [Persian].

28. Akkuş Y. Multiple sclerosis patient caregivers: the relationship between their psychological and social needs and burden levels. Disabil Rehabil. 2011;33(4):326-33. doi: 10.3109/09638288.2010.490866.

29. Rahimi A, Ahmadi F, Gholyaf M. effect of applying continuous care model on self-esteem in hemodialysis patients. Journal of Zanjan University of Medical Sciences and Health Services. 2005:16-21.

30. Sharifi Neyestanak ND, Ghodoosi Boroojeni M, Seyedfatemi N, Heydari M, Hoseini AF. Self esteem and its associated factors in patients with multiple sclerosis. Iran Journal of Nursing. 2012;25(78):14-22. [Persian].

31. Robati Z, Shareh H. The effectiveness of cognitive-behavioral group therapy in anxiety and self-esteem in patients with multiple sclerosis. Journal of Fundamentals of Mental Health. 2018;20(6):405-16. doi: 10.22038/jfmh.2018.11760.

32. Jones TM, Hush JM, Dear BF, Titov N, Dean CM. The efficacy of self-management programmes for increasing physical activity in community-dwelling adults with acquired brain injury ( $\mathrm{ABI})$ : a systematic review. Syst Rev. 2014;3:39. doi: 10.1186/20464053-3-39.

33. Kelly A, Ponsford J, Couchman G. Impact of a familyfocused intervention on self-concept after acquired brain injury. Neuropsychol Rehabil. 2013;23(4):563-79. doi: 10.1080/09602011.2013.795903.

34. Kidd T, Carey N, Mold F, Westwood S, Miklaucich M, Konstantara $\mathrm{E}$, et al. A systematic review of the effectiveness of self-management interventions in people with multiple sclerosis at improving depression, anxiety and quality of life. PLoS One. 2017;12(10):e0185931. doi: 10.1371/journal. pone.0185931 